\title{
Molecular Identification of Bloodmeal Source in Ixodes ricinus Ticks Using 12S rDNA As a Genetic Marker
}

\author{
PIERRE-FRANÇOIS HUMAIR, ${ }^{1}$ VÉRONIQUE DOUET,${ }^{1}$ FRANCISCA MORÁN CADENAS, ${ }^{1}$ \\ LEO M. SCHOULS, ${ }^{2}$ INGRID VAN DE POL, ${ }^{2}$ AND LISE GERN ${ }^{1,3}$
}

\begin{abstract}
J. Med. Entomol. 44(5): 869-880 (2007)
ABSTRACT We developed an efficient molecular method for the identification of the bloodmeal sources in the tick Ixodes ricinus (L.), the European vector of the agents of Lyme borreliosis and tick-borne encephalitis. $\mathrm{A} \approx 145$-bp orthologous fragment of the vertebrate mitochondrial $12 \mathrm{~S}$ rDNA was used as a molecular marker to discriminate host vertebrate species. The method consists of a single run polymerase chain reaction amplification of the $12 \mathrm{~S}$ rDNA molecular marker by using nondegenerate primers followed by a reverse line blot hybridization assay by using specific oligonucleotide probes. The palette of probes allowed us to distinguish major groups of host vertebrates (e.g., mammals, small rodents, artiodactyls, birds, lizards) and to identify the bloodmeal sources at the genus or species level. External primers were designed and used to sequence the $12 \mathrm{~S}$ rDNA molecular marker of a broad range of known or potential host vertebrate species $(n=60)$, including mammal $(n=28)$, bird $(n=31)$, and reptile $(n=1)$ species. The use of this technique coupled with known methods for identification of tick-borne pathogens (e.g., Borrelia burgdorferi sensu lato) allowed us to determine the source of infective bloodmeal and to identify reservoir species. The present method was successfully used to identify the source of bloodmeals in all feeding I. ricinus ticks and in half of questing field-collected I. ricinus ticks. Moreover, the bloodmeal source was identified in $65 \%$ of ticks infected with B. burgdorferi sensu lato. Further development of this technique may be envisaged for the detection of other vector-borne pathogens and their reservoir hosts.
\end{abstract}

KEY WORDS bloodmeal, host identification, tick, Ixodes ricinus, $12 \mathrm{~S}$ rDNA

To develop efficient control strategies toward vector-borne zoonoses, a clear understanding of the transmission dynamics of pathogens is needed. This requires an exhaustive identification of reservoir host species of these agents and an assessment on their respective role in habitats of interest. Among tick-borne zoonoses, Lyme borreliosis shows the most frequent occurrence in the Northern Hemisphere. In Europe, the etiological agent of Lyme borreliosis, Borrelia burgdorferi sensu lato (s.l.), is mainly vectored by the tick Ixodes ricinus (L.), and this pathogen is maintained through cycles involving ticks and vertebrate hosts such as mammals and birds (Gern and Humair 2002). European reservoirs of $B$. burgdorferi s.l. have been largely investigated since the first description of the pathogen in $I$. ricinus (Burgdorfer et al. 1983), and a provisional list of recognized reservoir and nonreservoir species has been drawn up (Gern et al. 1998, Gern and Humair 2002). However, this list is probably not exhaustive, and it may contain some inaccuracies

\footnotetext{
${ }^{1}$ Laboratory of Eco-Epidemiology, Institute of Biology, University of Neuchâtel, 2009 Neuchâtel, Switzerland.

${ }^{2}$ Laboratory for Vaccine-Preventable Diseases, National Institute for Public Health and the Environment, Bilthoven, The Netherlands.

${ }^{3}$ Corresponding author, e-mail: lise.gern@unine.ch.
}

due to the host identification procedure adopted. As a gold standard, reservoir identification implies animal trappings, temporary maintenance in captivity and use of tick xenodiagnosis. This procedure may increase the importance of small rodents as reservoirs, because these animals can be very easily trapped and maintained in captivity compared with birds and larger mammals. Indeed, tick xenodiagnosis has been largely used with small rodents (Aeschlimann et al. 1986; Matuschka et al. 1992; De Boer et al. 1993; Humair et al. 1993, 1999) but less frequently used with medium-sized mammals, birds, and reptiles (Matuschka et al. 1994, 1997; Kahl and Geue 1995; Craine et al. 1997; Gern et al. 1997; Humair and Gern 1998; Humair et al. 1998; Kurtenbach et al. 1998; Dsouli et al. 2006). As an alternative method, the assessment of the prevalence of borrelial infection in host feeding I. ricinus larvae or in derived nymphs (compared with the infection prevalence in questing larvae) may give indicative information on the infectivity of a particular vertebrate species for ticks, as shown for some species (Tälleklint and Jaenson 1994, Poupon et al. 2006).

Alternatively, the analysis of bloodmeals in vectors is an elegant and effective approach that was first explored for hematophagous Diptera, in particular, for 
mosquitoes, black flies and tsetse flies, by using immunological techniques (Tempelis 1975, Beier et al. 1988, Hunter and Bayly 1991, Clausen et al. 1998). Then, the use of polymerase chain reaction (PCR) techniques, such as heteroduplex analysis or multiplexed PCR, was introduced (Boakye et al. 1999, Lee et al. 2002, Ngo and Kramer 2003, Kent and Norris 2005). Methods for bloodmeal analysis in ticks have been developed with the use of a PCR amplification targeting the cytochrome $b$ gene coupled with sequencing (Tobolewski et al. 1992) or with a reverse line blot assay (RLB) (Kirstein and Gray 1996). The bloodmeal analysis in ticks faces the problem of accessibility of free-living ticks, which have recently fed. After their molt, questing ticks occur on the vegetation, and they may remain there for months, seeking for a host. Consequently, the quality and the quantity of bloodmeal remnants in questing ticks are both very poor. The sensitivity of the technique turned out to be crucial for the identification of bloodmeal source in ticks. Kirstein and Gray (1996) were able to detect host DNA in ticks up to $280 \mathrm{~d}$ postengorgement. More recently, Pichon et al. $(2003,2005)$ developed a similar technique targeting the nuclear 18S rRNA gene to discriminate major groups of vertebrate hosts.

We describe herein an efficient molecular method for the identification of $I$. ricinus bloodmeals by using a variable fragment of the mitochondrial 12S rRNA gene as a genetic marker. This marker allows at the same time to discriminate major groups of vertebrate hosts (e.g., mammals, birds, small rodents, artiodactyls, and lizards) and to identify the bloodmeal source at the genus or species level.

\section{Materials and Methods}

Search for an Adequate Molecular Marker. After assessment of various mitochondrial genes, $12 \mathrm{~S}$ rDNA sequences of various mammal and bird species that are known or potential hosts for I. ricinus ticks were retrieved from the GenBank database and aligned using ClustalX multi-alignment software. The interspecific or intergeneric genetic variability of the amplicon, the nondegenerate character of primers, and the small size of the amplicon were the three major criteria in the choice of an adequate molecular marker. Forward and reverse nondegenerate primers $(12 \mathrm{~S}-6 \mathrm{~F}$ and $12 \mathrm{~S}$ $9 \mathrm{R}$ ) were designed in conserved regions flanking a variable region (Table 1). The amplicon size was 143$150 \mathrm{bp}$. External nondegenerate primers (12S-12F and 12S-13R) also were designed for the complete sequencing of the $12 \mathrm{~S}$ rDNA marker of various vertebrate species (Table 1). Using the external primers, the amplicon was $612-635 \mathrm{bp}$ in size and included the $12 \mathrm{~S}$ rDNA target sequence.

Collection of Vertebrate Tissues. A large collection of vertebrate tissue samples was established during this study thanks to several collaborators (see Acknowledgments). This collection includes samples from various species of mammals and birds, and one species of reptile, which all belong to the vertebrate fauna of Switzerland and are known or potential hosts for I. ricinus. When possible, samples from different individuals coming from different locations in Switzerland were sequenced for each species to assess the intraspecific genetic variability of the $12 \mathrm{~S}$ rDNA marker.

Samples were taken from dead and frozen animals by using sterile scalpel blades and sterilized forceps. Tissue samples were generally taken from muscles or skin. For some species of small mammals, liver samples kept in alcohol were available. Tissue samples were subjected to DNA extraction, PCR amplification, and sequencing.

Collection of Field-Derived Feeding and Questing Ticks. Feeding ticks were collected from five species of mammals (Apodemus sylvaticus, Clethrionomys glareolus, Sciurus vulgaris, Capreolus capreolus, and Erinaceus europaeus) and from four species of birds (Turdus merula, Turdus philomelos, Sitta europaea, and Parus major). Ticks were identified to species, stage, and sex, and they were kept frozen at $-80^{\circ} \mathrm{C}$ until DNA extraction.

Questing nymph and adult I. ricinus ticks were collected by flagging the vegetation in a woodland in Neuchâtel, Switzerland, in spring 2005. Ticks were identified to species, stage, and sex, and they were maintained at relative humidity close to saturation $(\mathrm{RH}>95 \%)$ and at room temperature until DNA extraction. Questing ticks were analyzed for both host DNA and Borrelia identifications.

DNA Extraction. DNA was extracted from vertebrate muscle, skin, or liver tissues by using a DNeasy tissue kit (QIAGEN, Basel, Switzerland) according to the manufacturer's protocol. DNA was eluted in $200 \mu \mathrm{l}$ of elution buffer (QIAGEN), the DNA concentration was measured with a spectrophotometer, and DNA extracts were stored at $-20^{\circ} \mathrm{C}$ until further use.

Before DNA isolation, ticks were soaked in ethanol $70 \%$ and air-dried. DNA was extracted from unfed and feeding ticks by using a protocol described previously (Guy and Stanek 1991, Rijpkema et al. 1995). Briefly, feeding ticks were individually homogenized in $100 \mu \mathrm{l}$ of $0.7 \mathrm{M}$ ammonium hydroxide by using sterile filter tips or micropestles. Questing field-collected ticks were not homogenized, and they were placed as entire ticks in ammonium hydroxide. Tubes were incubated at $100^{\circ} \mathrm{C}$ for $15 \mathrm{~min}$. After a quick cooling, tubes were left open and incubated at $100^{\circ} \mathrm{C}$ for 15 min to evaporate the ammonia. Negative controls $(0.7 \mathrm{M}$ ammonium hydroxide without tick) were included during each DNA extraction procedure from ticks. Tick lysates were stored at $-20^{\circ} \mathrm{C}$ until use for PCR amplification.

PCR Amplification. Forward and reverse nondegenerate primers (12S-6F and B-12S-9R) (Table 1) were used to amplify the $\approx 145$-bp $12 \mathrm{~S}$ rDNA fragment that acts as molecular marker for the discrimination of vertebrates. PCR amplification was performed in a $50-\mu \mathrm{l}$ reaction volume containing a total of $3.0 \mathrm{mM}$ $\mathrm{MgCl}_{2}, 0.2 \mathrm{mM}$ dNTPs, $0.8 \mu \mathrm{M}$ of each primers, $1 \times \mathrm{Taq}$ buffer, $1.25 \mathrm{U}$ of TaqDNA polymerase (QIAGEN) and ultrafiltrated $\mathrm{H}_{2} \mathrm{O}$. Twenty microliters of tick lysates or $100 \mathrm{ng}$ of vertebrate DNA was used as template. 
Table 1. Oligonucleotide sequences of primers and probes used in PCR amplification and RLB assays

\begin{tabular}{|c|c|c|}
\hline $\begin{array}{l}\text { Oligonucleotide } \\
\text { primer or probe }\end{array}$ & Nucleotide sequence $\left(5^{\prime}-3^{\prime}\right)$ & Target organisms \\
\hline \multicolumn{3}{|l|}{ Primers } \\
\hline $12 \mathrm{~S}-6 \mathrm{~F}$ & CAAACTGGGATTAGATACC & Vertebrates \\
\hline B-12S-9R & 5'biotin-AGAACAGGCTCCTCTAG & Vertebrates \\
\hline $12 \mathrm{~S}-12 \mathrm{~F}$ & TGCCAGCCACCGCGGTCA & Vertebrates \\
\hline $12 \mathrm{~S}-13 \mathrm{R}$ & AGGAGGGTGACGGGCGGT & Vertebrates \\
\hline \multicolumn{3}{|l|}{ Probes } \\
\hline Mammal & 5'amino-AAAACTCAAAGGACTTGGC & Mammals \\
\hline Small rodent & 5'amino-GGCGGTACTTTATATCCAT & Muroidea (Muridae, Cricetidae) \\
\hline Artiodactyl & 5'amino-TATTCGCCAGAGTACTAC & Bovidae, Cervidae, Suidae \\
\hline Bird & 5' amino-TACGAGCACAAACGCTTAA & Birds \\
\hline Lizard & 5'amino-GAGAACTACAAGTGAAAAACT & Lizards \\
\hline Clethrionomys & 5'amino-AAACTTCAACATTTATAAAACAAAAG & Clethrionomys glareolus \\
\hline Apodemus & 5'amino-TAAACTTAAATAATTTAATAACAAAACTAT & Apodemus sylvaticus, A. flavicollis \\
\hline M. agrestis/Micromys & 5'amino-CTTAGCCCTAAACTTTAATAATT & Microtus agrestis, Micromys minutus \\
\hline M. arvalis & 5'amino-AAACCTCAATAATTTAGAAACAAAAA & Microtus arvalis \\
\hline M. minutus & 5'amino-AAACTTTAATAATTCCACAACAAAAT & Micromys minutus \\
\hline Mus & 5'amino-TGCTTAGCCATAAACCTAAAT & Mus musculus \\
\hline R. norvegicus & 5'amino-AACCTTAATAATTAAACCTACAAAAT & Rattus norvegicus \\
\hline R. rattus & 5'amino-ACCTTAATAATTACATCTACAAAAAT & Rattus rattus \\
\hline Sciurus & 5'amino-AACATAGACACTCAATTAACAAG & Sciurus vulgaris \\
\hline Glis & 5'amino-AAACCCTTACTAACGCAAC & Myoxus glis \\
\hline Lepus & 5'amino-TTAAACCTAAATAATTTCCTAACAAA & Lepus europaeus \\
\hline Erinaceus & 5'amino-GACAGTTACTTAACAAAATTGTA & Erinaceus europaeus \\
\hline Sorex sp. & 5'amino-AATACCCGCCAGAGAAC & Sorex araneus, S. alpinus, S. minutus, S. coronatus \\
\hline S. araneus & 5'amino-GGTATTTAACCTAACAAAAATAC & Sorex araneus \\
\hline S. minutus & 5'amino-ATCTAACAAGAATACCCGC & Sorex minutus \\
\hline Neomys sp. & 5'amino-ACAAAATTACTCGCCAGAG & Neomys anomalus, $N$. fodiens \\
\hline N. anomalus & 5'amino-TAAACTCAAGTAATTCACAAACA & Neomys anomalus \\
\hline T. europaea & 5'amino-ACCAAGACAATCAAGTTAACA & Talpa europaea \\
\hline Vulpes & 5'amino-CTATAACAAAACAATTCGCCA & Vulpes vulpes \\
\hline Meles & 5'amino-GATAACTCACAGAACAAAACT & Meles meles \\
\hline M. erminea & 5'amino-CATAAATAGTTCTAACAACAAAAC & Mustela erminea \\
\hline M. putorius & 5'amino-CTAAACATAAATAATTATCACAACAA & Mustela putorius \\
\hline Capreolus & 5'amino-CCTAAACACAAGTAATTAATATAACAA & Capreolus capreolus \\
\hline Sus & 5'amino-ACCCAAATAGTTACATAACAAAA & Sus scrofa \\
\hline Homo & 5'amino-ACCTCAACAGTTAAATCAACA & Homo sapiens \\
\hline Turdus/Parus & 5'amino-TGATGCTCGATATTACCTG & $\begin{array}{l}\text { Turdus merula, T. iliacus, T. philomelos, } \\
\text { T. pilaris, Parus major, P. caeruleus }\end{array}$ \\
\hline Erithacus & 5'amino-ATCTTGATGCTCCACCTTA & Erithacus rubecula \\
\hline Parus & 5'amino-TGAGCGTCCGCCTGA & Parus major, P. caeruleus \\
\hline P. ater & 5'amino-TTGATGCTTAACATTACCTGA & Parus ater \\
\hline Fringilla/Pyrrhula & 5'amino-TGATGCTTACCCCTACTAA & $\begin{array}{l}\text { Fringilla coelebs, F. montifringilla, Pyrrhula } \\
\quad \text { pyrrhula }\end{array}$ \\
\hline Prunella & 5'amino-TGATGCTTAACCCTACCTA & Prunella modularis \\
\hline Sitta & 5'amino-TATACAACCTAAGCATCCG & Sitta europaea \\
\hline Sylvia & 5'amino-GCTCGATCTTACTGGAG & Sylvia atricapilla \\
\hline Troglodytes & 5'amino-TGATGCTTTATATAACCCAAG & Troglodytes troglodytes \\
\hline Garrulus & 5'amino-TTGACACTCTATGCTACCT & Garrulus glandarius \\
\hline
\end{tabular}

Touch-down PCR conditions were used: initial denaturation step for $3 \mathrm{~min}$ at $94^{\circ} \mathrm{C}$, first cycle of $20 \mathrm{~s}$ at $94^{\circ} \mathrm{C}$, $30 \mathrm{~s}$ at $60^{\circ} \mathrm{C}$, and $30 \mathrm{~s}$ at $72^{\circ} \mathrm{C}$; the following cycles are identical except for the annealing temperature, which was lowered by $1^{\circ} \mathrm{C}$ at each cycle until it reached $52^{\circ} \mathrm{C}$, then 20 cycles (for vertebrate DNA extracts) or 40 cycles (for tick lysates) were carried out $\left(20 \mathrm{~s}\right.$ at $94^{\circ} \mathrm{C}$, $30 \mathrm{~s}$ at $52^{\circ} \mathrm{C}$, and $30 \mathrm{~s}$ at $72^{\circ} \mathrm{C}$ ) and a final extension step at $72^{\circ} \mathrm{C}$ for $7 \mathrm{~min}$. PCR products were stored at $4^{\circ} \mathrm{C}$ until use for reverse line blotting.

For sequencing, external forward and reverse primers (12S-12 F and 12S-13R) (Table 1) were used to amplify the $\approx 600$-bp $12 \mathrm{~S}$ rDNA fragment, including the complete molecular marker. The PCR amplification was carried out for 25 cycles (denaturation at $94^{\circ} \mathrm{C}$ for $30 \mathrm{~s}$, primer annealing at $60^{\circ} \mathrm{C}$ for $30 \mathrm{~s}$, and extension at $72^{\circ} \mathrm{C}$ for $1 \mathrm{~min}$ ) with initial denatur- ation step at $94^{\circ} \mathrm{C}$ for $2 \mathrm{~min}$ and a final extension step at $72^{\circ} \mathrm{C}$ for $10 \mathrm{~min}$. After amplification, the presence of PCR products was checked on a $1 \%$ agarose gel. PCR products were stored at $-20^{\circ} \mathrm{C}$ until use for sequencing.

All PCR amplifications were performed in a TGradient thermocycler (Biometra, Goettingen, Germany). For each PCR reaction, negative and positive controls were included. Great care was exercised to prevent contaminations. PCR setup, DNA extraction, sample additions, and PCR amplification and post-PCR analyses were performed in four separate rooms. PCR setup was done in a cabinet with built-in UV lamps. PCR setup and DNA extraction were performed in rooms restricted to this project only. Each area had its own dedicated set of pipettes and sterile filter tips. 
Table 2. Vertebrate species 12S rDNA sequences subjected to multi-alignment for search of molecular marker and probe design, and GenBank accession numbers

\begin{tabular}{|c|c|c|c|c|}
\hline Species $^{a}$ & Common name & $\begin{array}{l}\text { Amplicon } \\
\text { size (bp) }\end{array}$ & $\begin{array}{l}\text { No. sequenced } \\
\text { in this study }\end{array}$ & Accession nos. ${ }^{b}$ \\
\hline \multicolumn{5}{|l|}{ Mammals } \\
\hline Apodemus flavicollis* & Yellow-necked mouse & 144 & 2 & AJ311127, AJ311164, EF027238, EF027239 \\
\hline Apodemus sylvaticus* & Wood mouse & 144 & 2 & AJ311126, AJ311131, EF027240, EF027241 \\
\hline Arvicola terrestris* & Ground vole & 145 & 1 & EF027242 \\
\hline Bos taurus* & Cow & 145 & & V00654 \\
\hline Canis familiaris* & Dog & 144 & & U96639, AY012152, Y08507 \\
\hline Capra ibex* & Alpine ibex & 145 & & AY846815 \\
\hline Capreolus capreolus* & Roe deer & 145 & 2 & EF027243, EF027244 \\
\hline Cervus elaphus* & Red deer & 145 & & AF091707 \\
\hline Clethrionomys glareolus* & Bank vole & 144 & 4 & AJ250356, AJ005781, EF027245-EF027248 \\
\hline Crocidura russula & White-toothed shrew & 144 & 3 & AY769263, AY769264, EF027249-EF027251 \\
\hline Eliomys quercinus* & Garden dormouse & 143 & 1 & Y16896, EF027252 \\
\hline Equus caballus & Horse & 146 & & $\mathrm{X} 79547$ \\
\hline Erinaceus europaeus* & European hedgehog & 143 & 2 & $\mathrm{X} 88898, \mathrm{EF} 027253, \mathrm{EF} 027254$ \\
\hline Felis catus* & Cat & 146 & & U20753, AY012149, Y08503 \\
\hline Homo sapiens* & Human & 145 & & NC_001807 \\
\hline Lepus europaeus* & European hare & 144 & 2 & $\mathrm{AJ} 4 \overline{2} 1471, \mathrm{EF} 027255, \mathrm{EF} 027256$ \\
\hline Lynx lynx & Eurasian lynx & n.d. & & D28891 \\
\hline Meles meles* & Eurasian badger & 145 & 1 & Y08513, EF027257 \\
\hline Micromys minutus & Harvest mouse & 143 & 3 & AJ311139, EF027258-EF027260 \\
\hline Microtus agrestis* & Field vole & 144 & 4 & EF027261-EF027264 \\
\hline Microtus arvalis* & Common vole & 144 & 1 & EF027265 \\
\hline Microtus nivalis** & Snow vole & 144 & & X99464 \\
\hline Mus musculus ${ }^{c}$ & Mouse & 146 & 2 & X84382, EF027267, EF027268 \\
\hline Muscardinus avellanarius & Hazel dormouse & 143 & 3 & X84384, EF027269-EF027271 \\
\hline Mustela erminea* & Stoat/ermine & 145 & 1 & AF068553, EF027272 \\
\hline Mustela nivalis** & Least weasel & 145 & 1 & Y08515, AF068554, EF027273 \\
\hline Mustela putorius* & European polecat & 145 & 1 & Y08516, AF068550, U12844, EF027274 \\
\hline Myoxus glis* & Fat dormouse & 143 & 1 & AJ001562, X84385, EF027266 \\
\hline Neomys anomalus* & Miller's water shrew & 144 & 2 & $\begin{array}{l}\text { AF182177, AF182178, AF182173, AF182172, } \\
\text { EF027275, EF027276 }\end{array}$ \\
\hline Neomys fodiens* & Eurasian water shrew & 144 & 2 & AF182174, AF182175, EF027277, EF027278 \\
\hline Oryctolagus cuniculus* & Rabbit & 144 & & AJ001588 \\
\hline Ovis aries* & Sheep & 144 & & AF010406 \\
\hline Rattus norvegicus** & Brown rat & 145 & 1 & X14848, EF027279 \\
\hline Rattus rattus** & Black rat & 145 & & AJ005780 \\
\hline Sciurus vulgaris* & Red squirrel & 144 & 2 & AJ238588, EF027280, EF027281 \\
\hline Sorex alpinus* & Alpine shrew & 145 & 1 & EF027282 \\
\hline Sorex araneus* & Common shrew & 145 & 4 & AY012102, EF027283-EF027286 \\
\hline Sorex coronatus & Millet's shrew & 145 & 3 & EF027287-EF027289 \\
\hline Sorex minutus & Pigmy shrew & 145 & 3 & EF027290-EF027292 \\
\hline Sus scrofa* & Wild boar & 144 & 2 & AF034253, AJ002189, EF027293-EF027294 \\
\hline Talpa europaea* & European mole & 145 & 2 & Y19192, EF027295, EF027296 \\
\hline Vulpes vulpes* & Red fox & 144 & & Y08508 \\
\hline \multicolumn{5}{|l|}{ Birds } \\
\hline Buteo buteo* & Common buzzard & 146 & 2 & AF380305, U83719, EF027297, EF027298 \\
\hline Carduelis carduelis & European goldfinch & 147 & 1 & EF027299 \\
\hline Certhia brachydactyla* & Short-toed tree creeper & 147 & 1 & EF027300 \\
\hline Coccothraustes coccothraustes* & Hawfinch & 147 & 1 & EF027301 \\
\hline Corvus corone* & Carrion crow & 147 & & AF386463 \\
\hline Delichon urbica* & House martin & 146 & 1 & EF027302 \\
\hline Erithacus rubecula* & European robin & 147 & 2 & EF027303, EF027304 \\
\hline Falco tinnunculus* & Common kestrel & 148 & 1 & EF027305 \\
\hline Fringilla coelebs* & Chaffinch & 147 & 3 & AF407088, AF447231, EF027306-EF027308 \\
\hline Fringilla montifringilla* & Brambling & 147 & 1 & EF027309 \\
\hline Gallus gallus* & Chicken & 147 & & AY235571 \\
\hline Garrulus glandarius* & Eurasian jay & 147 & 1 & EF027310 \\
\hline Parus ater* & Coal tit & 147 & 2 & EF027311, EF027312 \\
\hline Parus caeruleus* & Blue tit & 147 & 1 & EF027313 \\
\hline Parus major* & Great tit & 147 & 2 & AY136557, EF027314, EF027315 \\
\hline Passer domesticus* & House sparrow & 147 & 2 & AF407085, AF447245, EF027316, EF027317 \\
\hline Passer montanus* & Tree sparrow & 145 & & AB042360 \\
\hline Perdix perdix** & Grey partridge & 145 & 1 & AF222590, EF027318 \\
\hline Phasianus colchicus* & Common pheasant & 145 & 1 & U83742, EF027319 \\
\hline Phoenicurus ochruros & Black redstart & 147 & 1 & EF027320 \\
\hline Phylloscopus collybita* & Common chiffchaff & 147 & 1 & EF027321 \\
\hline Phylloscopus trochilus* & Willow warbler & 147 & 2 & $\mathrm{AF} 407093, \mathrm{EF} 027322, \mathrm{EF} 027323$ \\
\hline Pica pica* ${ }^{*}$ & European magpie & 147 & 1 & EF027324 \\
\hline Picus viridis & Green woodpecker & 150 & 1 & EF027325 \\
\hline
\end{tabular}


Table 2. continued

\begin{tabular}{|c|c|c|c|c|}
\hline Species $^{a}$ & Common name & $\begin{array}{l}\text { Amplicon } \\
\text { size (bp) }\end{array}$ & $\begin{array}{l}\text { No. sequenced } \\
\text { in this study }\end{array}$ & Accession nos. ${ }^{b}$ \\
\hline Prunella modularis* & Dunnock/hedge accentor & 147 & 1 & AF407081, EF027326 \\
\hline Pyrrhula pyrrhula* & Eurasian bullfinch & 147 & 2 & EF027327, EF027328 \\
\hline Serinus serinus* & European serin & 147 & & AF 447255 \\
\hline Sitta europaea* & Eurasian nuthatch & 147 & 1 & AB042353, EF027329 \\
\hline Sturnus vulgaris* & Common starling & 147 & 1 & AF407091, EF027330 \\
\hline Sylvia atricapilla* & Blackcap & 147 & 3 & EF027331-EF027333 \\
\hline Troglodytes troglodytes* & Wren & 147 & 1 & EF027334 \\
\hline Turdus iliacus* & Redwing & 147 & 1 & EF027335 \\
\hline Turdus merula* & Blackbird & 147 & 3 & EF027336-EF027338 \\
\hline Turdus philomelos* & Song thrush & 147 & 1 & AF484935, EF027339 \\
\hline Turdus pilaris* & Fieldfare & 147 & 2 & EF027340, EF027341 \\
\hline \multicolumn{5}{|l|}{ Reptiles } \\
\hline Lacerta agilis* & Sand lizard & n.d. ${ }^{d}$ & & AF149947, AF080298 \\
\hline Lacerta viridis* & Green lizard & n.d. & & AF149958, AF149960-AF149962, AJ001480 \\
\hline Podarcis muralis & Wall lizard & 146 & 1 & $\begin{array}{l}\text { AF440603, AJ001468-AJ001470, AY190305 } \\
\text { EF027342, EF027343 }\end{array}$ \\
\hline
\end{tabular}

${ }^{a}$ Species marked with an asterisk $\left(^{*}\right)$ are known hosts for I. ricinus ticks in Switzerland (Aeschlimann 1972, Papadopoulos et al. 2002); species marked with 2 asterisks are known hosts for I. ricinus ticks in Europe (Arthur 1963, Matuschka et al. 1997).

${ }^{b}$ Sequences obtained from GenBank database or obtained in this study (accession numbers starting with EF).

${ }^{c}$ Laboratory host species.

${ }^{d}$ n.d., not determined due to incomplete sequence.

Sequencing of Vertebrate 12S rDNA Molecular Marker. The $\approx 600$-bp PCR products were purified with QIAquick PCR purification kit (QIAGEN). Cycle sequencing was performed using the dideoxy chain termination method by using an ABI Prism BigDye Terminator cycle sequencing kit (Applied Biosystems, Rotkreuz, Switzerland). Cycle sequencing parameters were as follows: denaturation at $96^{\circ} \mathrm{C}$ for $15 \mathrm{~s}$, primer annealing at $53^{\circ} \mathrm{C}$ for $15 \mathrm{~s}$, and extension at $60^{\circ} \mathrm{C}$ for 4 min. The cycle sequencing products were purified either by ethanol precipitation or with DyeEx spin columns (QIAGEN) and applied to an ABI Prism 310 genetic analyzer (Applied Biosystems). DNA sequences were checked with Sequence Navigator software (Applied Biosystems). Sequences from the same species were aligned with each other and with respective sequences from the GenBank database when available. The $12 \mathrm{~S}$ rDNA marker sequences of various vertebrates obtained in this study are available in the GenBank database under respective accession numbers (Table 2).

Sequence Analysis and Probe Design. The 143-150-bp $12 \mathrm{~S}$ rDNA marker sequences (newly sequenced or retrieved from the GenBank database) of various vertebrate species hosts for I. ricinus ticks were aligned using ClustalX multi-alignment software embl.net. Areas of genetic variability between species or between groups of vertebrates were used to design oligonucleotide probes using the Oligo software Primers 3.

Reverse Line Blot Hybridization. The reverse line blotting method for the identification of host DNA in ticks developed herein is based on the RLB technique described by Rijpkema et al. (1995)). Briefly, the probes were covalently linked to an activated Biodyne C membrane (Pall, Dreieich, Germany) by their $5^{\prime}$ amino group. For this purpose, the membrane was placed in a miniblotter system (Immunetics, Cambridge, MA), and line slots were filled with the different probes (100-500 pmol). After a quick incuba- tion (at least $1 \mathrm{~min}$ at room temperature), the excess of probes was removed, and the membrane was inactivated in $100 \mathrm{mM} \mathrm{NaOH}$ for $10 \mathrm{~min}$ (maximum) and washed in $2 \times$ SSPE buffer/0.1\% SDS (SSPE; Invitrogen, Basel, Switzerland) for $5 \mathrm{~min}$ at $60^{\circ} \mathrm{C}$. Then, the membrane was placed in the miniblotter, but the position of the membrane was $90^{\circ}$ rotated compared with the previous position. The slots were filled with the biotin-labeled heat-denatured PCR products, and the membrane was incubated for $60 \mathrm{~min}$ at $42^{\circ} \mathrm{C}$. Then, the PCR product solutions were removed, and the membrane was washed twice in $100 \mathrm{ml}$ of $2 \times \mathrm{SSPE} /$ $0.5 \%$ SDS for $10 \mathrm{~min}$ at $55^{\circ} \mathrm{C}$ and incubated with streptavidin-peroxidase conjugate (Roche Diagnostics, Rotkreuz, Switzerland) at $42^{\circ} \mathrm{C}$ for $30 \mathrm{~min}$. After a washing step, the membrane was incubated for 1-2 min. with enhanced chemiluminescence detection liquid (GE Healthcare, Otelfingen, Switzerland) and exposed to X-ray film Hyperfilm (GE Healthcare).

Detection and Identification of Borrelia Species in Ticks. For the detection and identification of $B$. burgdorferi s.l. species in ticks, we used the PCR and RLB hybridization method described previously (Alekseev et al. 2001, Burri et al. 2007). Oligonucleotide probes used are described in Poupon et al. (2006).

Statistical Analysis. Statistics were calculated with S-Plus 7.0 for Windows (Insightful Corp., Seattle, WA). The Fisher exact test was used to assess the success of the host DNA identification method between nymphs and adults (statistical significance, $P \leq$ $0.05)$.

\section{Results}

Sequencing and Alignment of $12 S$ rDNA Marker of Various Vertebrate Species. Using external primers, the $12 \mathrm{~S}$ rDNA molecular marker was sequenced for a broad range of vertebrate species belonging to the fauna of Switzerland: 28 species of mammals, 31 spe- 


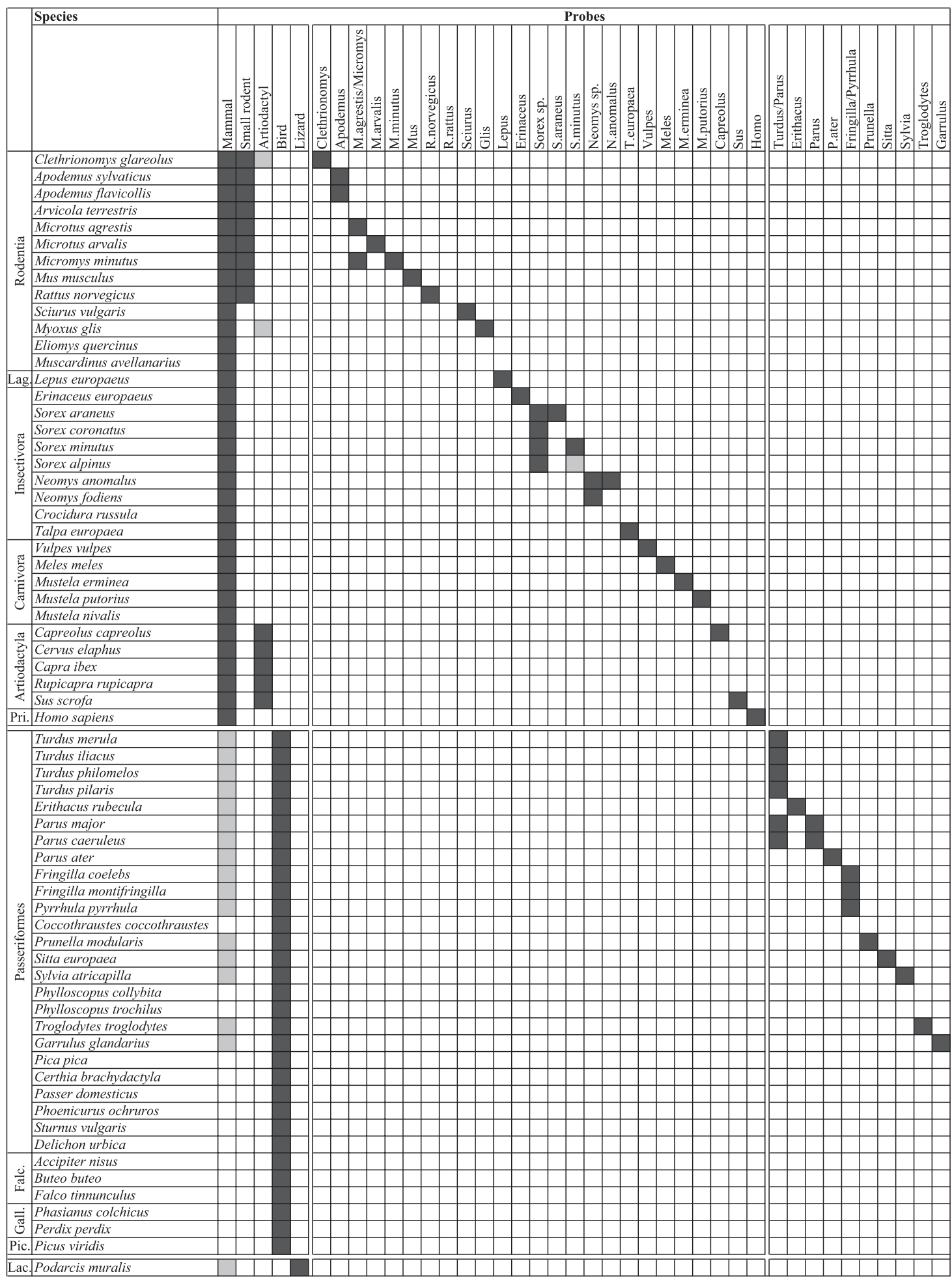

Fig. 1. Schematic representation of the RLB hybridization analysis of oligonucleotide probes with various host DNA. strong hybridization; 䀭, slight hybridization may occur. Falc., Falconiformes; Gall., Galliformes; Lac., Lacertidae; Lag. Lagomorpha; Pic. Piciformes; and Pri., Primates. 


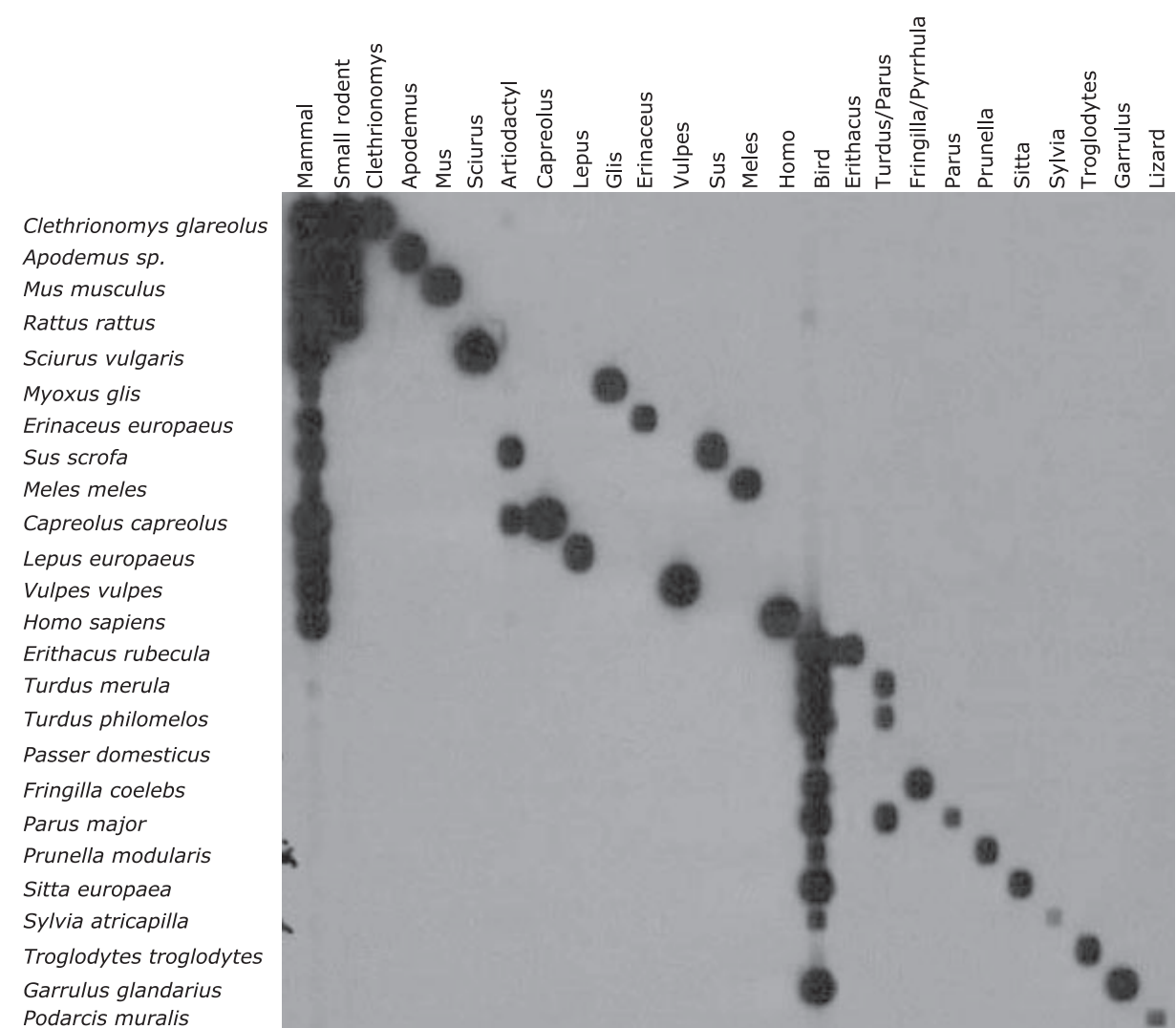

Fig. 2. Reverse line blot assay for the identification of vertebrate host species in host samples by using group- and species/genus-specific probes.

cies of birds, and one species of reptiles (Table 2). Some species are known hosts for I. ricinus ticks in Switzerland (Aeschlimann 1972, Papadopoulos et al. 2002, Poupon et al. 2006) and in Europe. If possible, sequences from two or more individuals of each species originating from different sites in Switzerland were obtained and aligned with sequences retrieved from the GenBank database if available. For a few species, only sequences from GenBank database were available. Overall, we aligned $12 \mathrm{~S}$ rDNA sequences from a large spectrum of vertebrate species including 42 species of mammals, 35 species of birds, and three species of reptiles (Table 2). According to the list of known host species of I. ricinus in Switzerland (Aeschlimann 1972, Papadopoulos et al. 2002, Poupon et al. 2006), only three species of mammals (Martes martes, Martes foina, and Rupicapra rupicapra) and 20 species of birds were missing.

The $12 \mathrm{~S}$ rDNA molecular marker shows very low intraspecies genetic variability. For genetic variability between sequences retrieved from GenBank and those obtained in this study, only sequences derived from vertebrates collected in Switzerland were considered for the consensus sequence.

Design of Specific Probes. The partial 12S rDNA consensus sequences of 42 species of mammals, 35 species of birds and three species of reptiles were multi-aligned to design specific probes. Five probes were designed to discriminate main groups of vertebrate hosts: mammals, birds, small rodents $(\mathrm{Mu}-$ roidea), lizards, and artiodactyls, which include Bovidae, Cervidae, and Suidae (Table 1). Twenty-four and 10 probes, respectively, were designed to identify major mammal and bird I. ricinus hosts at the genus or species level (Table 1). The design of species-specific probes seemed to be impossible for the discrimination of some species (e.g., Apodemus spp. and Turdus spp.).

Identification of Vertebrate DNA by RLB. To assess the specificity of the five group-specific probes and the 34 genus- or species-specific probes (Table 1), identification of vertebrate DNA by RLB was performed using DNA extracted from the aforementioned Swiss fauna tissue collection $(n=60)$ and from one laboratory species (Mus musculus) (Fig. 1). Overall, all probes showed a strong hybridization with the respective host DNA (Fig. 1). In a few cases, a weak cross-hybridization occurred, in particular with group-specific probes. The artiodactyl probe showed a weak cross-hybridization with vole DNA (C. glareolus) and dormouse DNA (Myoxus glis). The mammal probe showed a strong hybridization with all tested 


Small rodent
Artiodactyl
Bird
Lizard
Clethrionomys
Apodemus
M.agrestis
M.arvalis
M.minutus
R.norvegicus
R.rattus
Sciurus
Glis
Lepus
Erinaceus
Neomys sp.
N.anomalus
T.europaea
Vulpes
Meles
M.erminea
M.putorius
Capreolus
Sus
Turdus/Parus
Erithacus
Parus
P.ater
Fringilla/Pyrrhula
Prunella
Sitta
Sylvia
Troglodytes
Garrulus
S.araneus

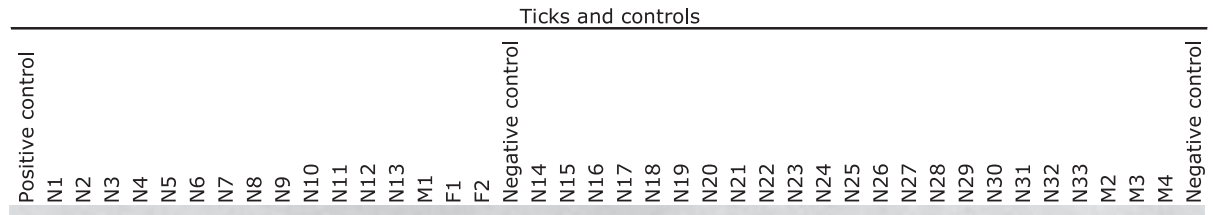

Small rodent

Bird

Lizard

Apodemus

M.agrestis

M.arvalis

Sciurus

Glis

Neomys sp.

N.anomalus

Vulpes

Meles

M.erminea

M.putorius

Turdus/Parus

Erithacus

Parus

Prunella

Troglodytes

S.araneus

Fig. 3. Reverse line blot assay for the identification of vertebrate host species in questing I. ricinus ticks (Neuchâtel, Switzerland) using group- and species/genus- specific probes. N, nymph; F, female; M, male; $\mathrm{X}$ and $\mathrm{H}$, different batches of ticks.

mammalian DNA, but turned out to be less specific because it weakly hybridized with DNA from 16 bird species as well as with DNA from a lizard species, Podarcis muralis. In contrast, the bird probe was highly specific and allowed to unambiguously discriminate avian hosts from nonavian hosts. The lizard probe was also highly specific. The other 34 probes allowed to clearly identify vertebrate hosts either at the genus level (e.g., the Apodemus probe) or at the species level (e.g., the M. putorius probe) (Fig. 1). The Turdus/ Parus probe and the Parus probe had to be used both to discriminate Turdus sp. DNA from Parus sp. DNA. In fact, the Turdus/Parus probe reacted to Turdus sp. and Parus sp., whereas the Parus probe reacted to Parus sp. only. Figure 2 shows the RLB hybridization patterns for some host species.

Host Identification in Feeding Ticks. Host identification was performed in nine I. ricinus ticks collected while feeding on five mammal and four bird species
(A. sylvaticus (one larva), C. glareolus (one larva), S. vulgaris (one nymph), E. europaeus (one female), C. capreolus (one female), T. merula (one nymph), T. philomelos (one nymph), P. major (one nymph), and $S$. europaea (one nymph). In all nine ticks, host DNA was present and showed a perfect hybridization pattern according to the probe specificity.

Host and Borrelia Identifications in Unfed FieldCollected Ticks. To assess the utility of the present host identification method under field conditions, nymphal and adult ticks collected in Neuchâtel were tested for the presence of host and Borrelia DNA (Fig. 3). The detection of host DNA in questing ticks required the use of a high number of PCR amplification cycles, and as a result, contamination with human DNA could not be avoided. Therefore, mammal and Homo probes for detection of mammalian and human DNA, respectively, were removed from our set of probes. 
Table 3. Host DNA identification in field-collected questing I. ricinus ticks by RLB assay (Neuchâtel, Switzerland)

\begin{tabular}{|c|c|c|c|c|}
\hline Host identification & & Nymphs & Adults & Total \\
\hline \multicolumn{5}{|l|}{ Group identification } \\
\hline Small rodents & & 1 & 1 & 2 \\
\hline Birds & & 3 & 4 & 7 \\
\hline Artiodactyls & & 5 & 3 & 8 \\
\hline Subtotal & & 9 & 8 & 17 \\
\hline \multicolumn{5}{|l|}{ Specific or generic identification } \\
\hline Clethrionomys glareolus & Bank vole & & 1 & 1 \\
\hline Sciurus vulgaris & Red squirrel & 5 & 11 & 16 \\
\hline Capreolus capreolus & Roe deer & 1 & 6 & 7 \\
\hline Sus scrofa & Wild boar & 3 & & 3 \\
\hline Mustela putorius & European polecat & & 3 & 3 \\
\hline Mustela erminea & Ermine & & 1 & 1 \\
\hline Erithacus rubecula & Robin & 1 & & 1 \\
\hline Turdus sp. & & & 1 & 1 \\
\hline Subtotal & & 10 & 23 & 33 \\
\hline \multicolumn{5}{|l|}{ Multiple identification } \\
\hline Artiodactyl/bird/European mole (T. europaea) & & 1 & & 1 \\
\hline Bird/red squirrel (S. vulgaris) & & 1 & & 1 \\
\hline Bird/wild boar (S. scrofa) & & & 1 & 1 \\
\hline Subtotal & & 2 & 1 & 3 \\
\hline Total & & 21 & 32 & 53 \\
\hline
\end{tabular}

In total, 55 nymphal, 28 male, and 26 female I. ricinus ticks were tested for host and Borrelia identifications. Host DNA could be detected in half of questing $I$. ricinus ticks (53/109; 48.6\%). Detection was significantly higher in adults $(32 / 54 ; 59.3 \%)$ than in nymphs $(21 / 55 ; 38.2 \%) \quad(P=0.035$; Fisher exact test $)$ and slightly varied between sexes (15/28 males; $53.6 \%$ and $17 / 26$ females; $65.4 \%$ ). For one third of the questing ticks with a bloodmeal identified $(17 / 53 ; 32.1 \%)$, host identification was possible only at the group level (small rodents [Muroidea], birds, or artiodactyls) (Table 3). For virtually two thirds of the I. ricinus ticks with identified host DNA (33/53; 62.3\%), host identification could be achieved at the species or genus level (Table 3). In three questing I. ricinus ticks, the presence of a mixture of DNA from two or three different hosts was observed (Table 3). Red squirrel (S. vulgaris) followed by roe deer (C. capreolus) were the species from which DNA was most frequently detected in questing ticks (Table 3). DNA from artiodactyls $(n=20)$ (including eight artiodactyls, seven C. capreolus, three S. scrofa and two multiple identifications), and rodents $(n=20)$ (including two Muroidea, 16 S. vulgaris, one C. glareolus, and one multiple identification) were most frequently detected followed by birds $(n=12)$ (including seven birds, one E. rubecula, one Turdus sp., and three multiple identifications) and carnivores $(n=4)$ (including three M. putorius and one M. erminea).

Borrelia infection was detected in 23/109 (21.1\%) questing I. ricinus ticks. In 15 of these 23 infected ticks $(65.2 \%)$, identification of the blood source was also possible (Table 4). In these ticks, single infection with $B$. burgdorferi sensu stricto $(n=5)$, Borrelia afzelii $(n=2)$, Borrelia garinii $(n=1)$, Borrelia valaisiana $(n=5)$, and untypeable Borrelia $(n=2)$ was observed (Table 4). No multiple infections were detected. $B$. burgdorferi ss and B. afzelii infections were observed with squirrel DNA, and B. valaisiana was observed with bird DNA. In ticks containing blood remnants from artiodactyls, DNA from B. afzelii, B. burgdorferi s.s., and B. valaisiana was detected (Table 4).

\section{Discussion}

This report describes the development of an efficient new technique for the identification of bloodmeal sources in the tick I. ricinus, the European vector of the agents of Lyme borreliosis and tick-borne encephalitis. The method consists of a single-run PCR amplification of the $12 \mathrm{~S}$ rDNA molecular marker using a single set of nondegenerate primers followed by RLB hybridization assay by using specific probes. This method allowed identifying the bloodmeal source in half of questing $I$. ricinus ticks collected from vegetation $(49 \%)$. This sensitivity was similar to those obtained in previous studies using $18 \mathrm{~S}$ rDNA as target (Pichon et al. 2003, 2005; Estrada-Peña et al. 2005). The identification to the genus or species level occurred for two thirds of ticks with bloodmeal identification. This represents a more precise identification compared with previous studies that identified host

Table 4. Bloodmeal source identification in $B$. burgdorferi s.l.-infected questing I. ricinus ticks (Neuchâtel, Switzerland)

\begin{tabular}{|c|c|c|c|c|c|}
\hline \multirow[b]{2}{*}{ Host identification } & \multicolumn{5}{|c|}{ No. infected I. ricinus ticks ${ }^{a}$} \\
\hline & $B b$ s.s. & $B a$ & $B g$ & $B v$ & $\begin{array}{c}\text { Borrelia } \\
\text { sp. }\end{array}$ \\
\hline Red squirrel & $2 \mathrm{~N}, 1 \mathrm{M}^{b}$ & $1 \mathrm{~N}$ & & & $1 \mathrm{~N}$ \\
\hline European polecat & $1 \mathrm{~F}$ & & & & \\
\hline Small rodents & & & & & $1 \mathrm{~F}$ \\
\hline Birds & & & & $2 \mathrm{~N}, 1 \mathrm{M}$ & \\
\hline Artiodactyls & $1 \mathrm{~N}$ & $1 \mathrm{~N}$ & & $1 \mathrm{~N}$ & \\
\hline Bird/wild boar & & & & $1 \mathrm{~F}$ & \\
\hline Artiodactyl/bird/mole & & & $1 \mathrm{~N}$ & & \\
\hline Total & 5 & 2 & 1 & 5 & 2 \\
\hline
\end{tabular}

${ }^{a}$ Ba, B. afzelii; Bb s.s., B. burgdorferi sensu stricto; Bg, B. garinii; Bv, B. valaisiana; and Borrelia sp., untypeable Borrelia.

${ }^{b} \mathrm{~N}$, nymph; M, male; and F, female. 
groups rather than host species (Pichon et al. 2003, 2005).

That questing ticks were collected at the beginning of the tick activity season (spring) suggests that the previous bloodmeal occurred during the previous tick activity season and that the method is sensitive enough to detect and identify the source of bloodmeals, which are several months old. A better sensitivity might be expected with the summer/autumnal tick cohort, as observed by Pichon et al. (2005). The identification of DNA from two or three different hosts in a single tick suggests that interrupted feeding may occur in I. ricinus. Possibly, this may contribute to the transfer of tick-borne pathogens. However, such transmission probably rarely occurs.

Coupled with the RLB method for the detection and identification of B. burgdorferi s.l. (Alekseev et al. 2001, Poupon et al. 2006, Burri et al. 2007), the host identification technique could confirm the existence of associations between hosts and Borrelia genospecies, notably between red squirrels, B. burgdorferi s.s., and B. afzelii (Humair and Gern 1998) as well as between birds, B. garinii, and B. valaisiana (Humair et al. 1998). Currently, our sample sizes are too small to confirm previous observations. The presence of $B$. afzelii, B. valaisiana, and B. burgdorferi s.s. in ticks in which artiodactyl blood remnants were detected was more surprising, because these hosts are generally considered zooprophylactic (Gern and Humair 2002). One explanation may be that these ticks have been infected through cofeeding transmission of the pathogens from infected to uninfected ticks feeding on uninfected artiodactyls (Hu et al. 2003). The overall prevalence of Borrelia infection in ticks $(21.1 \%)$ in this study was similar to prevalences observed in other tick populations in Switzerland (Jouda et al. 2003, 2004a,b; Burri et al. 2007).

The target gene for the identification of bloodmeal sources is the $12 \mathrm{~S}$ rRNA gene, which encodes for the small subunit ribosomal RNA in mitochondria. Mitochondrial DNA (mtDNA) presents peculiar features, such as lack of recombination, maternal inheritance, and presence of orthologous genes, and it has been used extensively in phylogenetic and evolutionary studies. In addition, mtDNA occurs in high copy numbers in a eukaryote cell; therefore, is a molecule of choice when analyzing small quantity of degraded biological material, as in the case of bloodmeal remnants in tick midguts. The $12 \mathrm{~S}$ rRNA gene was investigated because it is described with some tRNAs as the most conserved regions of the mitochondrial genome (Saccone et al. 1999). Various authors have used the cytochrome $b$ gene as a molecular marker to identify bloodmeals in Diptera (Boakye et al. 1999, Lee et al. 2002, Ngo and Kramer 2003) and in ticks (Tobolewski et al. 1992, Kirstein and Gray 1996). A preliminary analysis (unpublished) demonstrated that the cytochrome $b$ gene is subject to a high inter- and intraspecific genetic variability, which could have lead to a problematic probe and primer design for the large spectrum of I. ricinus hosts. However, the nuclear $18 \mathrm{~S}$ rRNA gene, used in other studies (Pichon et al. 2003,
2005; Estrada-Peña et al. 2005), is too much conserved to identify the genus or species origin of tick bloodmeals.

The small size of the molecular marker is crucial for the host identification in questing ticks. In the case of degraded DNA, as occurs in questing ticks, an inverse correlation exists between the efficiency of PCR amplification and the size of the amplicon (Kirstein and Gray 1996). The nondegenerate character of primers avoids mispriming and enhances the specificity of DNA amplification reaction. High interspecies or intergenus genetic variability and a low intraspecies polymorphism of the molecular marker allow a precise identification of the hosts that ticks have been feeding on.

The palette of oligonucleotide probes used in the RLB allowed at the same time to distinguish major groups of host vertebrates and to identify bloodmeal sources at the genus or species level. Forty oligonucleotide probes were designed to identify groups, genera or species that may serve as natural or laboratory hosts for I. ricinus. The analysis of various vertebrate DNA samples from our tissue library demonstrated that the specificity of the method was very good and allowed a correct identification of a large range of host species. However, in some cases, the precise identification at the species level was not possible. For mammals, for example, the Apodemus probe did not permit to distinguish A. flavicollis from A. sylvaticus, and the M. agrestis/Micromys probe did not discriminate $M$. agrestis and M. minutus. For some avian hosts, the specificity was even lower as in the case of the Turdus/ Parus probe that reacts to four Turdus species and two Parus species. The concurrent use of the Parus probe is necessary to distinguish Turdus sp. from Parus sp.

The sensitivity of the technique becomes crucial when analyzing host-seeking I. ricinus ticks collected from the vegetation. Host blood remnants in fieldcollected tick midguts come from the previous instar, may be several months old and are present in small quantity and in a degraded state. To enhance the technique's sensitivity, the number of PCR amplification cycles was increased. The use of nested PCR was avoided because of the high risk of contaminations with products from the first PCR run. Using the 40cycle PCR procedure, human contamination was very frequent. Therefore, the mammal and the Homo probes were discarded when analyzing field-collected ticks. In addition, to avoid any other contamination, extremely strict conditions were applied to the method. For example, PCR setup and DNA extraction were performed in rooms dedicated to this use and restricted to this project.

In conclusion, the present technique based on PCR amplification of a $12 \mathrm{~S}$ rDNA molecular marker and RLB hybridization assays provides a rapid and accurate method for determining the source of bloodmeals in I. ricinus ticks collected in the field. This method could be used to identify new host species of arthropod vectors. Coupled with methods for identification of vector-borne pathogens, this technique should allow researchers to determine the source of infective 
bloodmeal, identify reservoir hosts at the species level, and assess the importance of a host species in a habitat. Further development of this technique may be envisaged for other arthropod vectors.

\section{Acknowledgments}

We thank Martin Zimmerli and Blaise Mulhauser (Muséum d'Histoire Naturelle, Neuchâtel); Michel Beaud (Musée d'Histoire Naturelle, Fribourg); Peter Vogel, Jacques Hausser, and Patrick Basset (Département d'Ecologie et d'Evolution, Lausanne); Marie-Angèle Poupon and Ilona Loubry (Institut de Biologie, Neuchâtel); Georg Brosi and Erwin Eggenberger (Amt für Jagd und Fischerei, Graubünden); Arthur Fiechter (Service de la Faune, Neuchâtel); Claude Fischer, Matisse, and the Zoo de la Garenne for help in the collection of vertebrate tissue samples. We thank Yves Cheminade for technical assistance, the Laboratoire de Botanique évolutive (University of Neuchâtel) for the use of the sequencer, and Yong-Min Yuan for help with the sequencer. This project was supported by the Swiss National Science Foundation 3200-057098 and 3200B0-100657. V.D. and P.F.H. were supported by the Swiss National Science Foundation. P.-F.H. was also supported by the Roche Foundation and the Novartis Foundation for Medicine and Biology.

\section{References Cited}

Aeschlimann, A. 1972. Ixodes ricinus, Linné, 1758 (Ixodoidea: Ixodidae). Essai préliminaire de synthèse sur la biologie de cette espèce en Suisse. Acta Trop. 29: 321-340.

Aeschlimann, A., E. Chamot, F. Gigon, J. P. Jeanneret, D. Kesseler, and C. Walther. 1986. Borrelia burgdorferi in Switzerland. Zentbl. Bakt. Hyg. A. 263: 450-458.

Alekseev, A. N., H. V. Dubinina, I. Van de Pol, and L. M. Schouls. 2001. Identification of Ehrlichia spp. and Borrelia burgdorferi in Ixodes ticks in the Baltic regions of Russia. J. Clin. Microbiol. 39: 2237-2242.

Arthur, D. R. 1963. British ticks. Butterworths, London, United Kingdom.

Beier, J. C., P. V. Perkins, R. A. Wirtz, J. Koros, D. Diggs, T. P. Gargan II, and D. K. Koech. 1988. Bloodmeal identification by direct enzyme-linked immunosorbent assay (ELISA), tested on Anopheles (Diptera: Culicidae) in Kenya. J. Med. Entomol. 25: 9-16.

Boakye, D. A., J. Tang, P. Truc, A. Merriweather, and T. R. Unnasch. 1999. Identification of bloodmeals in haematophagous Diptera by cytochrome B heteroduplex analysis. Med. Vet. Entomol. 13: 282-287.

Burgdorfer, W., A. G. Barbour, S. F. Hayes, O. Péter, and A. Aeschlimann. 1983. Erythema chronicum migrans-a tick-borne spirochetosis. Acta Trop. 40: 79-83.

Burri, C., F. Morán Cadenas, V. Douet, J. Moret, and L. Gern. 2007. Ixodes ricinus density and infection prevalence with Borrelia burgdorferi sensu lato along a north-facing altitudinal gradient in the Rhône Valley (Switzerland). Vector Borne Zoonotic Dis. 7: 50-58.

Clausen, P. H., I. Adeyemi, B. Bauer, M. Breloeer, F. Salchow, and C. Staak. 1998. Host preferences of tsetse (Diptera: Glossinidae) based on bloodmeal identifications. Med. Vet. Entomol. 12: 169-180.

Craine, N. G., P. A. Nuttall, A. C. Marriott, and S. E. Randolph. 1997. Role of grey squirrels and pheasants in the transmission of Borrelia burgdorferi sensu lato, the Lyme disease spirochaete, in the UK. Folia Parasitol. 44: 155-160.

De Boer, R., K. E. Hovius, M. K. Nohlmans, and J. S. Gray. 1993. The woodmouse (Apodemus sylvaticus) as a reser- voir of tick-transmitted spirochetes (Borrelia burgdorferi) in The Netherlands. Zentralbl. Bakteriol. 279: 404416.

Dsouli, N., H. Younsi-Kabachii, D. Postic, S. Nouira, L. Gern, and A. Bouattour. 2006. Reservoir role of lizard Psammodromus algirus in transmission cycle of Borrelia burgdorferi sensu lato (Spirochaetaceae) in Tunisia. J. Med. Entomol. 43: 737-742.

Estrada-Peña, A., J. J. Osácar, B. Pichon, and J. S. Gray. 2005. Host and pathogen detection for immature stages of $I x$ odes ricinus (Acari: Ixodidae) in north-central Spain. Exp. Appl. Acarol. 37: 257-268.

Gern, L., E. Rouvinez, L. N. Toutoungi, and E. Godfroid. 1997. Transmission cycles of Borrelia burgdorferi sensu lato involving Ixodes ricinus and/or I. hexagonus ticks and the European hedgehog, Erinaceus europaeus, in suburban and urban areas in Switzerland. Folia Parasitol. 44: 309-314.

Gern, L., A. Estrada-Peña, F. Frandsen, J. S. Gray, T. G. Jaenson, F. Jongejan, O. Kahl, E. Korenberg, R. Mehl, and P. A. Nuttall. 1998. European reservoir hosts of Borrelia burgdorferi sensu lato. Zentralbl. Bakteriol. 287: 196-204.

Gern, L., and P.-F. Humair. 2002. Ecology of Borrelia burgdorferi sensu lato in Europe, pp. 149-174. In J. S. Gray, O. Kahl, R. S. Lane, and G. Stanek [eds.], Lyme borreliosis: biology, epidemiology, and control. CAB International, Wallingford, Oxon, United Kingdom.

Guy, E. C., and G. Stanek. 1991. Detection of Borrelia burgdorferi in patients with Lyme disease by the polymerase chain reaction. J. Clin. Pathol. 44: 610-611.

Hu, C. M., Y. Cheminade, J.-L. Perret, V. Weynants, Y. Lobet, and L. Gern. 2003. Early detection of Borrelia burgdorferi sensu lato infection in Balb/c mice by co-feeding Ixodes ricinus ticks. Int. J. Med. Microbiol. 293: 421-426.

Humair, P. F., N. Turrian, A. Aeschlimann, and L. Gern. 1993. Borrelia burgdorferi in a focus of Lyme borreliosis: epizootiologic contribution of small mammals. Folia Parasitol. 40: 65-70.

Humair, P.-F., and L. Gern. 1998. Relationship between Borrelia burgdorferi sensu lato species, red squirrels (Sciurus vulgaris) and Ixodes ricinus in enzootic areas in Switzerland. Acta Trop. 69: 213-227.

Humair, P.-F., D. Postic, R. Wallich, and L. Gern. 1998. An avian reservoir (Turdus merula) of the Lyme borreliosis spirochetes. Zentralbl. Bakteriol. 287: 521-538.

Humair, P. F., O. Rais, and L. Gern. 1999. Transmission of B. afzelii from Apodemus mice and Clethrionomys voles to Ixodes ricinus ticks: differential transmission pattern and overwintering maintenance. Parasitology 118: 33-42.

Hunter, F. F., and R. Bayly. 1991. ELISA for identification of blood meal source in black flies (Diptera: Simuliidae). J. Med. Entomol. 28: 527-532.

Jouda, F., M. Crippa, J.-L. Perret, and L. Gern. 2003. Distribution and prevalence of Borrelia burgdorferi sensu lato in Ixodes ricinus ticks of canton Ticino (Switzerland). Eur. J. Epidemiol. 18: 907-912.

Jouda, F., J.-L. Perret, and L. Gern. 2004a. Ixodes ricinus density, and distribution and prevalence of Borrelia burgdorferi sensu lato infection along an altitudinal gradient. J. Med. Entomol. 41: 162-169.

Jouda, F., J. L. Perret, and L. Gern. 2004b. Density of questing Ixodes ricinus nymphs and adults infected by Borrelia burgdorferi sensu lato in Switzerland: spatio-temporal pattern at a regional scale. Vector Borne Zoonotic Dis. 4: 23-32.

Kahl, O., and L. Geue. 1995. Laboratory study on the role of the European fox, Vulpes vulpes, as a possible reservoir of Borrelia burgdorferi s.l., pp. 239. In Proceedings, 2nd In- 
ternational Conference on Tick-Borne Pathogens at the Host-Vector Interface: a global perspective, 28 August-1 September 1995, Kruger National Park, South Africa.

Kent, R. J., and D. E. Norris. 2005. Identification of mammalian blood meals in mosquitoes by a multiplexed polymerase chain reaction targeting cytochrome B. Am. J. Trop. Med. Hyg. 73: 336-342.

Kirstein, F., and J. S. Gray. 1996. A molecular marker for the identification of the zoonotic reservoirs of Lyme borreliosis by analysis of the blood meal in its European vector Ixodes ricinus. Appl. Environ. Microbiol. 62: 4060-4065.

Kurtenbach, K., D. Carey, A. N. Hoodless, P. A. Nuttall, and S. E. Randolph. 1998. Competence of pheasants as reservoirs for Lyme disease spirochetes. J. Med. Entomol. 35: $77-81$.

Lee, J. H., H. Hassan, G. Hill, E. W. Cupp, T. B. Higazi, C. J. Mitchell, M. S. Godsey, Jr., and T. R. Unnasch. 2002. Identification of mosquito avian-derived blood meals by polymerase chain reaction-heteroduplex analysis. Am. J. Trop. Med. Hyg. 66: 599-604.

Matuschka, F. R., P. Fischer, M. Heiler, D. Richter, and A. Spielman. 1992. Capacity of European animals as reservoir hosts for the Lyme disease spirochete. J. Infect. Dis. 165: $479-483$.

Matuschka, F.-R., H. Eiffert, A. Ohlenbusch, and A. Spielman. 1994. Amplifying role of edible dormice in Lyme disease transmission in central Europe. J. Infect. Dis. 170: 122-127.

Matuschka, F. R., S. Endepols, D. Richter, and A. Spielman. 1997. Competence of urban rats as reservoir hosts for Lyme disease spirochetes. J. Med. Entomol. 34: 489-493.

Ngo, K. A., and L. D. Kramer. 2003. Identification of mosquito bloodmeals using polymerase chain reaction (PCR) with order-specific primers. J. Med. Entomol. 40: 215-222.

Papadopoulos, B., P. F. Humair, A. Aeschlimann, C. Vaucher, and W. Büttiker. 2002. Ticks on birds in Switzerland. Acarologia 42: 3-19.
Pichon, B., D. Egan, M. Rogers, and J. Gray. 2003. Detection and identification of pathogens and host DNA in unfed host-seeking Ixodes ricinus L. (Acari: Ixodidae). J. Med. Entomol. 40: 723-731.

Pichon, B., M. Rogers, D. Egan, and J. Gray. 2005. Bloodmeal analysis for the identification of reservoir hosts of tick-borne pathogens in Ireland. Vector-Borne Zoonotic Dis. 5: 172-180.

Poupon, M.-A., E. Lommano, P.-F. Humair, V. Douet, O. Rais, M. Schaad, L. Jenni, and L. Gern. 2006. Prevalence of Borrelia burgdorferi sensu lato in ticks collected from migratory birds in Switzerland. Appl. Environ. Microbiol. 72: $976-979$.

Rijpkema, S. G., M. J. Molkenboer, L. M. Schouls, F. Jongejan, and J. F. Schellekens. 1995. Simultaneous detection and genotyping of three genomic groups of Borrelia burgdorferi sensu lato in Dutch Ixodes ricinus ticks by characterization of the amplified intergenic spacer region between 5S and 23S rRNA genes. J. Clin. Microbiol. 33: 3091-3095.

Saccone, C., C. De Giorgi, C. Gissi, G. Pesole, and A. Reyes. 1999. Evolutionary genomics in Metazoa: the mitochondrial DNA as a model system. Gene 238: 195-209.

Tälleklint, L., and T.G.T. Jaenson. 1994. Transmission of Borrelia burgdorferi s.l. from mammal reservoirs to the primary vector of Lyme borreliosis, Ixodes ricinus (Acari: Ixodidae), in Sweden. J. Med. Entomol. 31: 880-886.

Tempelis, C. H. 1975. Host-feeding patterns of mosquitoes, with a review of advances in analysis of blood meals by serology. J. Med. Entomol. 11: 635-653.

Tobolewski, J., M. J. Kaliszewski, R. K. Colwell, and J. H. Oliver, Jr. 1992. Detection and identification of mammalian DNA from the gut of museum specimens of ticks. J. Med. Entomol. 29: 1049-1051.

Received 7 March 2007; accepted 5 June 2007. 